\title{
A study of maternal and perinatal outcome in induction of labour at 40 weeks and 41 weeks of gestation
}

\author{
Ranjana Patil*, Anupama Dave
}

MGM Medical College Indore, Madhya Pradesh, India

Received: 13 June 2016

Accepted: 02 July 2016

\section{*Correspondence:}

Dr. Ranjana Patil,

E-mail: patildrranjana@gmail.com

Copyright: ( ) the author(s), publisher and licensee Medip Academy. This is an open-access article distributed under the terms of the Creative Commons Attribution Non-Commercial License, which permits unrestricted non-commercial use, distribution, and reproduction in any medium, provided the original work is properly cited.

\begin{abstract}
Background: To study and compare the maternal and perinatal outcome of induction of labour in pregnancies at 40 week and 41 week of gestation.

Methods: 150 pregnant women who completed 40 weeks of pregnancy and were screened through exclusion and exclusion criteria .They were induced with intracervical PGE2 gel. Maternal and perinatal outcomes were determined and compared in 40 week group (40+0 - 40+6days) and 41week group (41+0-41+6 days).

Results: Prolongation of pregnancy is observed frequently in nulliparous women in both the groups (74\% vs $62 \%$ ). Caesarian rates were more in 41 week group compared to 40 week group (30\% vs $12 \%$, $\mathrm{p}=0.007)$. Maternal outcome in terms of PPH, perineal tears and sepsis are observed more in 41 week group though it was not statistically significant $(\mathrm{p}=0.493)$. Birth asphyxia, MAS and MSL are factors responsible for worse perinatal outcome in 41 week group that was statistically significant $(\mathrm{p}=0.009)$. Age and duration of labour showed no difference in both groups.

Conclusions: Labour induction should be done at 40 weeks - it is reasonable option because it prevents a lot of maternal and perinatal complications.
\end{abstract}

Keywords: Induction of labour, 40 week, 41 weeks

\section{INTRODUCTION}

Post-term pregnancy is the pregnancy that has extended to or beyond 42 weeks (294 days) of gestation. ${ }^{1}$ Approximately 5 to 10 percent continue to at least 42 week's gestation. ${ }^{2}$

Post-term pregnancies are associated with numerous adverse outcomes.

Maternal risks include emergent caesarean delivery, vacuum extraction or forceps delivery, cephalopelvic disproportion, cervical rupture, perineal lacerations, dystocia, large fetus, fetal death, postpartum hemorrhage. Neonatal risks are asphyxia, aspiration, admission to intensive care after birth, bone fracture, peripheral nerve paralysis and others., ${ }^{2,3-5}$
It has been shown that maternal complications of pregnancy could increase after 40 weeks' gestation in low-risk women, especially nullipara. ${ }^{6}$ In low-risk pregnancy at term, it has been suggested that active management of risk through the use of preventive labour induction prior to possible development of uteroplacental insufficiency or cephalo-pelvic disproportion can improve birth outcomes and reduce caesarean section rates. $^{7,8}$ Since women in Asia and Africa have been shown to have a shorter duration of pregnancy compared with European women the authors of this appraisal recommend that clinicians in those regions should regard recommendation No. 1 (IOL for women known with certainty to have reached 41 weeks of gestation) as strong. ${ }^{9-11}$ The authors believe that the evidence which forms the basis for this recommendation was inadequate in terms of representation of Asian and African women in the studies. There may also be situations in which IOL 
may need to be considered earlier in Asian and African women if uteroplacental insufficiency or cephalopelvic disproportion is suspected especially in nullipara.

In under-resourced settings where ultrasound scanning facilities are not available to date pregnancies accurately, there would be a need to educate and motivate pregnant women to attend prenatal clinics early to allow clinical dating of the pregnancy. On the other hand, there is no rationale for IOL. Further evidence is required regarding benefits and undesirable effects of IOL between 38 and 41 weeks. $^{7,8}$

A policy of labour induction after 41 completed weeks or later, compared to awaiting spontaneous labour for at least one week (42 completed weeks), is associated with fewer perinatal deaths and meconium aspiration syndrome, without an increased risk of caesarean section (A). ${ }^{12}$

Centres vary in the availability of tests for fetal surveillance and the ability to cope with the demand. Based on these factors, it is difficult to have a uniform policy for management of post term pregnancy.

Considering the above literature, we have done a study to compare the effect of induction of labour at 40 weeks and 41 weeks. Objective of the study was to compare maternal and fetal outcome after induction in two groups: women who induced at 40 week group $(40+0-40+6$ days) and women who induced at 41 week group $(41+0-$ 41+6days).

\section{METHODS}

The present study was carried out in OBGYN department, MGM Medical College Indore (M.P.) during the period from $1^{\text {st }}$ February 2014 to $31^{\text {st }}$ March 2015.

This was a prospective and comparative study. In order to obtain relatively low risk pregnancies, every case had to pass through exclusion and inclusion criteria.

\section{Inclusion criteria}

- Maternal age group 15-44 years.

- Singleton pregnancy, reliable dates, previous regular menstrual cycles.

- Cases in which gestational dating is confirmed by ultrasonography performed between 12-22 weeks of pregnancy.

\section{Exclusion criteria}

- Maternal age groups <15 and > 44 years.

- Unknown dates, irregular menstrual cycles, anomalous fetus, malpresentation, maternal complications like pre-eclampsia, diabetes and

- Cardiac diseases in pregnancy.
- All women who reported in spontaneous labour.

Study adhered to ICMR guidelines of experiments on human participants and the subjects were included after obtaining informed consent. Approval from ethical committee has been taken prior to study. This study is not funded by any source.

Totally 150 cases who attended the antenatal clinic and labour room fulfilled the criteria's and were included in the study. Induction was done with intracervical PGE2 gel.

The data were collected, analysed and comparison was done between the two group. Statistical analyses were performed the using statistical programmes SPSS for Windows (version 20.1). All variables were analysed using chi-square test. The $p$ value less than 0.05 considered statistically significant.

\section{RESULTS}

After analysis, we arrived at the following results:

\section{Gestational age wise distribution}

In the present study, there were $60 \%$ cases belonging to 40 week group and $40 \%$ cases to 41 week group.

\section{Age wise distribution}

There were $56 \%$ vs $65 \%$ and $31 \%$ vs $18 \%$ of patients contributed for age group of 21-25 years and15-20years respectively in both groups.

Table 1: Mode of delivery.

\begin{tabular}{|c|c|c|c|c|c|}
\hline \multirow[t]{2}{*}{$\begin{array}{l}\text { Mode of } \\
\text { delivery }\end{array}$} & \multicolumn{2}{|c|}{40 week $(n=90)$} & \multicolumn{2}{|l|}{$\begin{array}{l}41 \text { week } \\
(n=60)\end{array}$} & \multirow[t]{2}{*}{$\begin{array}{l}\mathbf{P} \\
\text { value }\end{array}$} \\
\hline & Number & $\%$ & Number & $\%$ & \\
\hline Vaginal & 79 & 88 & 42 & 70 & $0.007 *$ \\
\hline LSCS & 11 & 12 & 18 & 30 & $0.007 *$ \\
\hline
\end{tabular}

${ }^{*} \mathrm{p}<0.05$, Result significant (Chi Square test applied).

Table 2: Duration of labour.

\begin{tabular}{|c|c|c|c|c|}
\hline \multirow{2}{*}{$\begin{array}{l}\text { Duration of } \\
\text { labour (hrs) }\end{array}$} & \multicolumn{2}{|c|}{40 week $(n=79)$} & \multicolumn{2}{|c|}{41 week $(n=42)$} \\
\hline & Number & $\%$ & Number & $\%$ \\
\hline$<6$ hours & 19 & 24 & 11 & 26 \\
\hline 7-12 hours & 54 & 68 & 22 & 53 \\
\hline$>12$ hours & 6 & 8 & 9 & 2 \\
\hline
\end{tabular}

\section{Parity distribution}

In the present study prolonged pregnancy occurred more frequently in primigravida than in multigravida. About $69 \%$ cases belonged to primigravida and $31 \%$ cases belonged to multigravida. Among 40 week group $74 \%$ of 
cases belonged to primigravida and $26 \%$ in multigravida. Among 41 week group $62 \%$ of cases belonged to primi and $38 \%$ of cases in multi.

\section{Mode of delivery}

Rate of CS and vaginal delivery were $12 \%$ vs $88 \%$ and $30 \%$ vs $70 \%$ in 40 week and 41 week group respectively. Rate of caesarian section were more in 41 week group (30\%vs12\%, p value $\leq 0.007)$, so it is statistically significant.

Table 3: Maternal morbidity.

\begin{tabular}{|lllll|}
\hline \multirow{2}{*}{ Complication } & \multicolumn{3}{c}{40 week GA } & \multicolumn{2}{c|}{ 41 week GA } \\
\cline { 2 - 5 } & No. & $\%$ & No. & $\%$ \\
\hline PPH & 2 & 2 & 3 & 5 \\
\hline Cervical tear & 2 & 2 & 1 & 2 \\
\hline Perineal tear (IIo - IIIo) & 1 & 1 & 1 & 2 \\
\hline Sepsis & 2 & 2 & 3 & 5 \\
\hline
\end{tabular}

Using Chi Sqare test: $\mathrm{p}=0.493$; Result not significant.

\section{Duration of labour}

In present study majority of patients 68\%vs $53 \%$ delivered in 7-12 hrs duration in 40 week group and 41 week group respectively. While cases delivered in $>12$ hrs duration were $21 \%$ in 41 week and $8 \%$ in 40 week group.

Table 4: Perinatal Morbidity.

\begin{tabular}{|lllll|}
\hline \multirow{2}{*}{ Complication } & \multicolumn{3}{c}{$\mathbf{4 0}$ week GA } & \multicolumn{3}{l|}{ (1)eek GA } \\
\cline { 2 - 5 } & No. & $\%$ & No. & $\%$ \\
\hline Birth Asphyxia & 4 & 4 & 3 & 5 \\
\hline MAS & 2 & 2 & 4 & 7 \\
\hline MSL & 2 & 2 & 5 & 8 \\
\hline
\end{tabular}

Using Chi Square test: $\mathrm{p}=0.009$. Result significant.

\section{Maternal morbidity}

Maternal morbidity in terms of $\mathrm{PPH}$, cervicaltear, perineal tear and Sepsis were 2\%vs 3\%, $2 \%$ vs $2 \%, 1 \%$ vs $2 \%$ and $2 \%$ vs $5 \%$ in 40 week and 41 week group respectively. On statistical analysis p value is 0.493 , so maternal outcome in terms of morbidity is not significant.

\section{Perinatal morbidity}

Perinatal morbidity as Birth asphyxia, MAS,MSL were $4 \%$ vs $5 \%, 2 \%$ vs $4 \%$ and $2 \%$ vs $8 \%$ in 40 week and 41 week group respectively. On comparison, it is found statistically significant as p value is 0.009 .

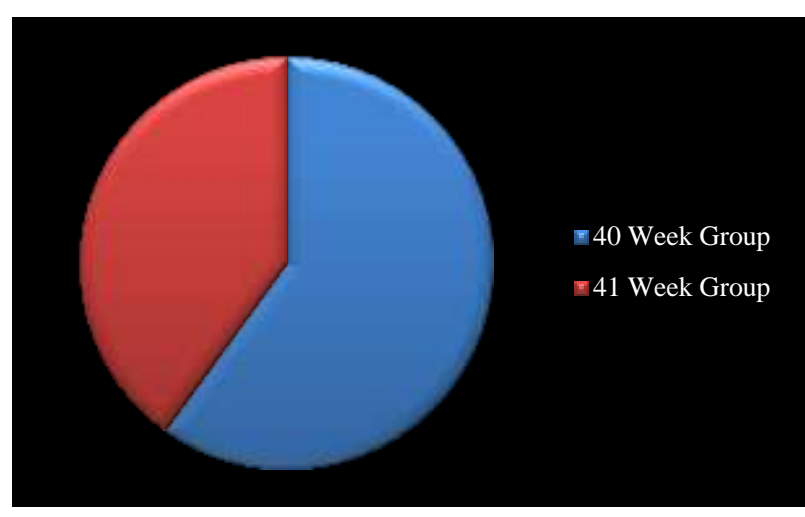

Figure 1: Gestational age wise distribution.

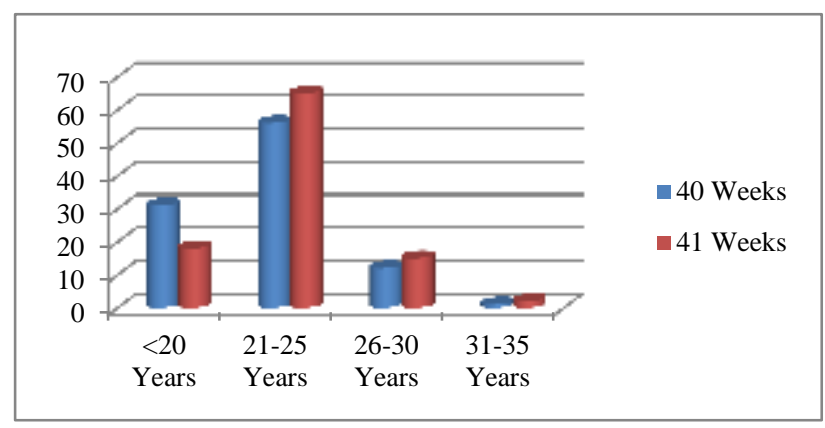

Figure 2: Age wise distribution of cases in 40 week and 41 week group.

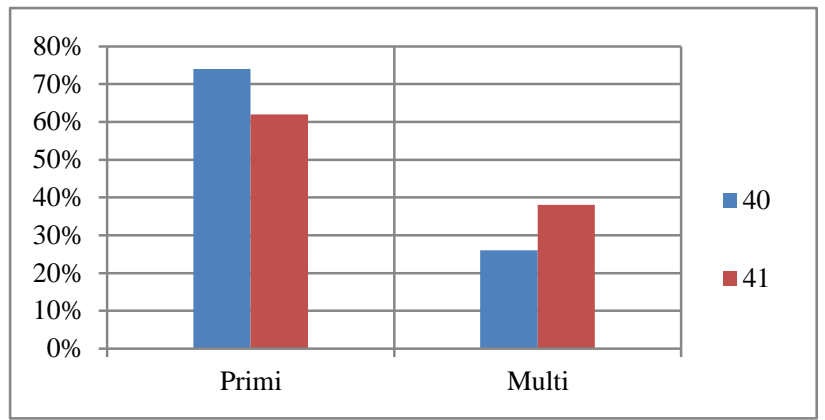

Figure 3: Parity wise distribution of cases in $\mathbf{4 0}$ week and 41 week group.

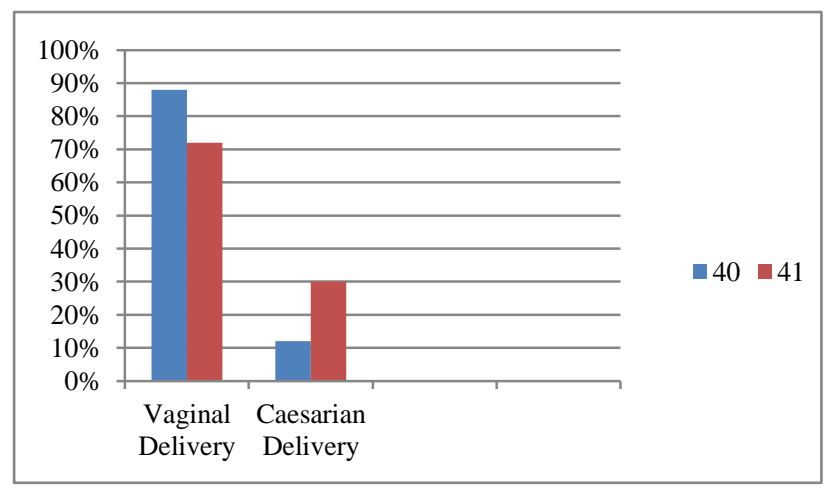

Figure 4: Mode of delivery in 40 week and 41 week group. 


\section{DISCUSSION}

\section{Gestation age wise distribution}

Our centre is tertiary referral centre so majority of cases were referred from distant areas and further follow-up not feasible and therefore we included them in 40 week group. In present study 40 week and 41 week groups are contributing $60 \%$ and $40 \%$ of cases repectively. Shinge et al reported $44 \%$ and $34 \%$ cases in 40 and 41 week group. ${ }^{13}$

\section{Age wise distribution}

In present study there is no age difference in both groups while there is inverse relationship between age and incidence of prolonged pregnancy in Shinge'study. ${ }^{13}$

\section{Parity distribution}

In present study prolonged pregnancy occurred more frequently in primigravida $(74 \%, 62 \%)$ than multigravida $(26 \%, 38 \%)$ in both groups. Similar observation made by Mahapatro et al where $72 \%$ vs $28 \%$ were primi and multi .However no significant difference was seen in James M Alaxander study in prolonged pregnancy. ${ }^{14,15}$

\section{Mode of delivery}

Overall vaginal delivery rates were more in both groups ( $88 \%$ vs $70 \%$ ) but caesarian section rates were more in 41 week group $(30 \%)$ in comparision to 40 week group $(12 \%)$.Very same observation was made by Paliulyte et al where caesarian rates were $22 \%$ vs $10 \%$ in 41 weeks and 40 week group respectively. Mahapatro et al also observed that rate of LSCS were more in 41 week group (38\% vs $26 \%) .{ }^{14,16}$ Operative interferences were more because of foetal distress, failed induction and prolonged labour.

\section{Duration of labour}

Duration of labour in both groups were same as in study by Paliulyte et al. ${ }^{16}$ While according to Shinge et al duration of labour is longer in 41 week group. ${ }^{13}$

\section{Maternal outcome}

Maternal morbidity like increased rate of caesarian section, $\mathrm{PPH}$, perineal tear, sepsis and cervical tear are more common in 41 week group in compare to 40 week group. This is attributed by more caesarian section rates in 41 week group. Though it is not statistically significant. Our findings - corroborates with Paliulyte et al while AB Caughey and JT Bishop et al found more morbidities in their study. ${ }^{6,16}$

\section{Perinatal outcome}

Perinatal morbidity like birth asphyxia (5\% vs $4 \%$ ), MAS (7\% vs $2 \%$ ), MSL (8\% vs $2 \%$ ) are more frequent in 41 week group. The risk of asphyxia was 3\%vs2\% in 41 and 40 week in Paliulyte et al. ${ }^{16}$ The incidence of MSL were $29 \%$ vs $16 \%$ in 41 and 40 weeks in study by Mahapatro et al. So more vigilant and careful fetal monitoring is required in 41 week group. $^{14}$

\section{CONCLUSION}

Our study clearly demonstrates that maternal outcome in the form of caesarian rates, and perinatal outcome in form of birth asphyxia, MSL, MAS are more frequent in 41 week group in compare to 40 week group. As our country is developing one where infrastructure and resources are limited while patients load is much more so intensive intrapartum monitoring not feasible. Another important factors are lack of awareness and poor compliance for follow up on patient's part. So considering above factors labour induction should be at 40 weeks as a reasonable option because it prevents a lot of maternal and perinatal complications.

Funding: No funding sources

Conflict of interest: None declared

Ethical approval: The study was approved by the Institutional Ethics Committee

\section{REFERENCES}

1. Delaney M, Roggensack A, Leduc DC, Ballermann $\mathrm{C}$, Biringer A, Delaney $\mathrm{M}$ et al. Guidelines for the management of pregnancy at $41+0$ to $42+0$ weeks. SOGC clinical practice guidelines. JOGC. 2008:214:800-8

2. Briscoe D, Nguyen H, Mencer M, Gautam N, Kalb DB. Management of pregnancy beyond 40 weeks gestation. Am Fam Physician. 2005;71(10):1935-41.

3. Caughey AB, Bishop JT. Maternal complications of pregnancy increase beyond 40 weeks of gestation in low-risk women. J Perinatol. 2006;26(9):540-5.

4. Olesen AW, Westergaard JG, Olsen J. Perinatal and maternal complications related to postterm delivery: a national register-based study, 1978-1993. Am J Obstet Gynecol. 2003;189(1):222-7.

5. Heimstad R, Romundstad PR, Eik-Nes SH, Salvesen KA. Outcomes of pregnancy beyond 37 weeks of gestation. Obstet Gynecol. 2006;108(3):500-8.

6. Caughey AB, Bishop JT. Maternal complications of pregnancy increase beyond 40 weeks of gestation in low-risk women. Journal of Perinatology. 2006;26(9):540-5.

7. Nicholson JM, Caughey AB, Stenson MH, Cronholm PF, Kellar LC, Bennet I. The active management of risk in multiparous pregnancy at term: association between a higher prevention labour induction rate and improved birth outcomes. American Journal of Obstetrics and Gynaecology. 2009;200:e1-250-13.

8. Nicholson MD, Kellar LC, Cronholm PF, Macones GA. Active management of risk in pregnancy at term in an urban population: an association between a higher induction of labor rate and a lower Caesarean 
delivery rate. American Journal of Obstetrics and Gynaecology. 2004;191:1516-28.

9. Patel RR, Steer P, Doyle P, Little MP, Elliot P. Does gestation vary by ethnic group? A London-based study of over 122,000 pregnancies with spontaneous onset of labour. International Journal of Epidemiology. 2004;32(1):107-13.

10. Mathai M, Thomas S, Peedicayil A, Regi A, Jasper P, Joseph R. Growth pattern of the Indian fetus. International Journal of Gynaecology and Obstetrics. 1995;48:21-4.

11. Goonewardene M, Rameez MFM, Kaluarachchi A, Perera H. WHO recommendations for induction of labour: RHL commentary. The WHO Reproductive Health Library; Geneva: World Health Organization.

12. Resnik R, Calder A. Post Term Pregnancy. Maternal fetal medicine, $4^{\text {th }}$ edn. Robert K. Creasy and Robert Resnik, W.B. Saunders; Philadelphia. 1999:532-7.

13. Shinge N, Kumar V. Comparative study of maternal and fetal outcome in pregnancies of GA 40 completed weeks and beyond. Journal of Evolution of Medical and Dental Sciences. 2013;2(25):450915.

14. Mahapatro A, Samal S. Fetomaternal outcome in pregnancy beyond 40 week. International Journal of Pharma and Bio Science.2015;6(2):(B)53-8.

15. Alexander JM, McIntire DD, Leveno KJ. "Forty weeks and beyond: pregnancy outcomes by week of gestation". Am J obstet and Gynaec. 2000;96:291-4.

16. Paliulyte V, Ramasauskaite D. Labour induction in postdate pregnancy. When to start at 40 or 41 Gestaion? Acta Medica Lituanicia. 2010:17(1).

Cite this article as: Patil R, Dave A. A study of maternal and perinatal outcome in induction of labour at 40 weeks and 41 weeks of gestation. Int $\mathbf{J}$ Reprod Contracept Obstet Gynecol 2016;5:2704-8. 